\title{
Method of managing the agricultural resource potential of agrolandscapes
}

\author{
Evgeny Kuznetsov ${ }^{1}$, Anna Khadzhidi ${ }^{1}$, Andrey Novikov ${ }^{2}$, Margarita Kuznetsova ${ }^{1}$, Arsen \\ Kurtnezirov $^{1}$,Lyudmila Kravchenko ${ }^{3 *}$, and Violetta Kochkina ${ }^{1}$ \\ ${ }^{1}$ Kuban State Agrarian University named after I. T. Trubilin, 13, Kalinina str, 350044, \\ Krasnodar, Russia \\ ${ }^{2}$ All-Russian Research Institute of Irrigative Agriculture, 9, Timirjaseva str, 400002, \\ Volgograd, Russia \\ ${ }^{3}$ Don State Technical University, 1, Gagarin sq., 344003, Rostov-on-Don, Russia
}

\begin{abstract}
The authors developed the methods of managing the agroresource potential of agrolandscapes based on the risks of managing resource-adapted technologies. They established the limits of the applicability of technologies according to the critical dimensionless risk indicator. The model of the resource state of the agrolandscape for managing quantitative indicators of the reclamation state of the soil has been obtained. They optimized risk indicators using the Harrington desirability function which allows to make more adequate decisions on managing the agro-resource potential of agrolandscapes. The desirability function allows not only to determine the quantitative reclamation state by the desirability risks, but also find the qualitative change in the resource over time depending on the technologies used.
\end{abstract}

\section{Introduction}

The agro-resource potential of agroandscapes (ARPL) is defined by the land reclamation status (LRS), which determines fertility and can also serve as a land degradation indicator [1]. It is important to be aware of the reclamation state of the agro-resource potential of agrolandscapes, what resource-adapted technologies should be applied and what complexes of reclamation machines for tillage, e.g. for the construction of mole drains or slits for the removal of excess water from the soil, should be used [2]. The resource potential of the agrolandscape, which determines the wintering of winter crops, the timely sowing of agricultural crops in the spring, the removal of water from crops during heavy rains that cause waterlogging in the summer, depends on the timely removal of water from the fields. With the lack of implementation of complex measures on agrolandscapes the producer faces the risks of not obtaining the planned yield and, as a result, the business turns to unprofitable $[3,4]$.

* Corresponding author: 1usya306@yandex.ru 
LRS risks should be understood as how the resource of the LRS agrolandscape will be changed by the application of adapted technologies. When exposed to technologies on the landscape, the energy change of the substance of the agrolandscape occurs. It is reflected in fertility change, content of macro-and micronutrients, water salinity, degree of salinity of arable horizon of the soil. Thus, it is necessary to control ARPL, i.e. to manage the LRS risks that are inevitable when the adapted technologies are applied to the resources of the agrolandscape [5,6].

Modern agricultural technologies of precision farming, multi-depth plowing of the soil, etc., improve yields of agricultural crops [7]. However, there is a degradation of land fertility in chernozem soils. Humus content has decreased over 40-60 years from about 8 to 4-6 mg/100g. LRS is degraded, which is compensated by the introduction of mineral and organic fertilizers in doses calculated by the removal of nutrients from the soil $[8,9]$. The more intensive the technologies are, the more nutrients are removed from the soil with the crop. This shows that no matter what precise, adapted or any other technologies have been applied, the degradation of the soil cover remains the major problem of modern agriculture $[10,11]$. To protect land from the negative impact on the fertile soil layer, a method that allows integrated and systematic management of the reclamation resource of agrolandscapes has been developed. The LRS system management is based on the risks of loss of soil fertility which are numerical dimensionless indicators, when exceeded, the degradation process in the soil from the applied technologies is sure to start. It is followed by the unstable development of agricultural landscapes. One of the major tasks is to prevent the beginning of the degradation process or to improve the LRS of the agrolandscape soils. Therefore, there is such a critical LRS barrier which, when exceeded, leads to the degradation of ARPL.

\section{Method}

The methodology is based on the critical reclamation state of the agrolandscape taxon which, when exceeded, causes conditions for the transition of the LRS to a new reclamation state, which determines the degradation of the taxon using an integrated risk indicator. This barrier should be considered as a dimensionless critical integrated risk indicator (KIIR). The KIIR value includes a set of specific risks that can be managed and thus affect the fertility of the agrolandscape with resource-adapted technologies. The agrolandscape is divided into taxa of rectangular or triangular shape with a side length of 50 to $100 \mathrm{~m}$, depending on the size of the field. At the vertices of taxa, the integrated risk indicator is determined by the formula:

$$
I I R i=\frac{\sum_{1}^{n} I i}{\sum n}
$$

where IIRi is the dimensionless integrated risk indicator at the top of the taxon; Ii is the dimensionless risk indicators; $\mathrm{n}$ is the number of risk indicators.

The reclamation status of the taxon is determined by the formula [1]: 


$$
I I R k=\frac{\sum_{1}^{k} I I R i}{\sum k} \leq K I I R k
$$

where IIRk is the dimensionless integrated risk indicator of taxon; KIIRk is the dimensionless critical integrated risk indicator, above which a stable state of the taxon is broken; $\mathrm{k}$ is the number of integrated risk indicators of the taxon.

The reclamation state of the sustainable agrolandscape development is determined by the critical integrated risk indicator. The IIRk indicator is taken as the critical parameter of the risk indicator, at which the agricultural landscape goes into a state of degradation. Let's establish the transition of the agricultural landscape from sustainable development to degradation by IIRk. For this purpose we will develop a "risk safety scale" (SSR), which is used to control the agro-resource potential of the agrolandscape. The SSR scale is formed by the IIRi indicators. Each indicator is assigned a numerical parameter to assess the reclamation state of the resource and its energy state. For "perfect" LRS the indicator of 1.0 is assigned. For example, for 8 indicators that will determine the "perfect" status of the taxon at IIRi in relative units, it will also equal 1.0, that follows from formula (1).

Table 1. Assessment of risk indicators by the reclamation state of the soil in the arable horizon of the agro landscape.

\begin{tabular}{|c|c|c|c|c|}
\hline Indicator & $\begin{array}{l}\text { Reclamation state of the agricultural } \\
\text { landscape LRS }\end{array}$ & Parameter value & $\begin{array}{l}\text { Unit of } \\
\text { measurement }\end{array}$ & Indicator score \\
\hline 1 & $\begin{array}{l}\text { Occurrence of the ground water level in } \\
\text { the agricultural landscape area at a depth } \\
\text { of } 0 \text { and more than } 2.5 \mathrm{~m}\end{array}$ & $\begin{array}{l}0.5-1.0 \\
1.0-1.5 \\
1.5-2.5 \\
>2.5\end{array}$ & $\mathrm{~m}$ & $\begin{array}{l}4 \\
3 \\
2 \\
1\end{array}$ \\
\hline 2 & $\begin{array}{l}\text { Acid-base balance }(\mathrm{pH}) \text { in the arable } \\
\text { horizon of the soil }\end{array}$ & $\begin{array}{l}4.5-5.5 \\
5.5-6.5 \\
6.5-7.5 \\
7.5-8.0\end{array}$ & - & $\begin{array}{l}3 \\
2 \\
1 \\
2\end{array}$ \\
\hline 3 & Humus content in the arable soil horizon & $\begin{array}{l}6.0-8.0 \\
5.0-6.0 \\
4.0-5.0 \\
<4.0\end{array}$ & $\%$ & $\begin{array}{l}1 \\
2 \\
3 \\
4\end{array}$ \\
\hline 4 & $\begin{array}{l}\text { Availability of hydrolyzable nitrogen in } \\
\text { the arable soil horizon }\end{array}$ & $\begin{array}{l}2.0-3.0 \\
3.0-4.0 \\
4.0-5.0 \\
>5.0\end{array}$ & $\mathrm{mg} / 100 \mathrm{~g}$ & $\begin{array}{l}4 \\
3 \\
2 \\
1\end{array}$ \\
\hline 5 & $\begin{array}{l}\text { Availability of mobile phosphorus in the } \\
\text { arable soil horizon }\end{array}$ & $\begin{array}{c}0.5-1.0 \\
1.0-2.0 \\
2.0-3.0 \\
>3.0\end{array}$ & $\mathrm{mg} / 100 \mathrm{~g}$ & $\begin{array}{l}4 \\
3 \\
2 \\
1\end{array}$ \\
\hline 6 & $\begin{array}{l}\text { Availability of mobile potassium in the } \\
\text { arable soil horizon }\end{array}$ & $\begin{array}{l}5-10 \\
10-20 \\
20-30 \\
>30\end{array}$ & $\mathrm{mg} / 100 \mathrm{~g}$ & $\begin{array}{l}4 \\
3 \\
2 \\
1\end{array}$ \\
\hline 7 & $\begin{array}{l}\text { The content of aggregates in the arable } \\
\text { soil horizon }\end{array}$ & $\begin{array}{l}70-55 \\
55-40 \\
40-20 \\
<20\end{array}$ & $\%$ & $\begin{array}{l}4 \\
3 \\
2 \\
1\end{array}$ \\
\hline 8 & $\begin{array}{l}\text { Degree of soil salinity in the arable soil } \\
\text { horizon: } \\
\text { nonsaline soils } \\
\text { weak } \\
\text { medium } \\
\text { strong }\end{array}$ & $\begin{array}{l}\text { Less than } 0.15 \\
0.15-0.30 \\
0.30-0.40 \\
0.40-0.60\end{array}$ & $\%$ & $\begin{array}{l}1 \\
2 \\
3 \\
4\end{array}$ \\
\hline
\end{tabular}

Note. Assessments of soil LRS monitoring by risk indicators: 1-2 - good; 2-3-satisfactory; 3-4unsatisfactory; $>4$-soil degradation. 
Agroresource potential assessment is performed by the risk indicators depending on the energy status of taxon (table 1).

The major risk indicators for resource-adapted technologies for processing the arable soil horizon, waste disposal by sprinkling on agricultural irrigation fields, irrigation reclamation include: mechanical composition of the arable soil horizon - I2; availability of mobile potassium - I2; availability of mobile phosphorus - I3; availability of hydrolyzable nitrogen - I4; humus content- I5; acid - base balance of the soil $(\mathrm{pH})$ - I6; degree of soil salinity - I7; ground water level at the agrolandscape area- I8; water-air state of the soil- I9; flooding area of the agrolandscape - I10; salinity of ground water- I11. Indicators (I1 - I 8) are used in monitoring and managing the increase of the LRS of the arable soil horizon.Indicators (I6,I 8 - I11) are used to control the elimination of flooding and waterlogging of agrolandscapes.

According to rank each LRS is assigned an assessment dimensionless indicator from 1 to 4 , depending on the energy state of the taxon. The reclamation state of the agricultural landscape is considered perfect if each risk indicator is equal to 1 . It should be noted that during the transition of the LRS from 1 to 2, there is a significant deterioration of the ARPL. It follows that the integrated risk indicator IIRi of 2 is the critical IIRk. Taking this into account the SSR scale has been developed (Table 2).

Table 2 - (SSR) at IIR

\begin{tabular}{|l|l|l|}
\hline Technologies risks & \multicolumn{1}{|c|}{$\begin{array}{c}\text { Reclamation status of the } \\
\text { agrolandscape }\end{array}$} & $\begin{array}{l}\text { Risk assessment of } \\
\text { the agrolandscape }\end{array}$ \\
\hline$I I R=1$ & no risks & "perfect" \\
\hline $1<I I R \leq 2$ & not exposed to risks & "good" \\
\hline $2<I I R \leq 3$ & in an unstable state & "satisfactory" \\
\hline $3<I I R \leq 4$ & in a critical state & "unsatisfactory" \\
\hline$I I R>4$ & is degrading & degradation \\
\hline
\end{tabular}

Each ARPA state exposed to technologies is assessed by the IIR on the SSR scale (Table 2 ). For the "perfect" state, the risk measure is estimated at IIR $=1.0$. At $1<\operatorname{IIR} i \leq 2$, the state corresponds to "good". If the state is satisfactory, the risk measure is in the range of 2 $<\mathrm{IIR} \leq 3$. At $3<\mathrm{IIR} \leq 4$-the agricultural landscape is considered to be in an unsatisfactory state (the agrolandscape is in the process of degradation) and at IIR $>4.0$-degradation (disaster).

The risk safety scale (SSR) (Table 2) was optimized using the Harrington method. The Harrington desirability function is applied to optimize indicators and shows that integrated risk indicators (1), which can be numerous ( I1, I2 .. I n , I n+1 ...), adequately correspond to the desirability of $\mathrm{d} 1, \mathrm{~d} 2 \ldots \mathrm{dn} d \mathrm{n}+1 \ldots$ [12]. Desirability function $\mathrm{d}(\mathrm{x})$ by limitations of the indicators of reclamation state of soil can be represented as follows:

$$
\begin{gathered}
d(x)=e^{-e^{-(x-2)}} . \\
(0)<d(x)<1),
\end{gathered}
$$

where $d(x)$ is the desirability function; $x$ is a dimensionless value linearly related to indicator I. 
We set the levels of desirability that the LRS will correspond to on the risk safety scale (Tables 1, 2). The lower level of desirability is assumed to be equal to 0.2 , which corresponds to the unsatisfactory state of the LRS (it is not desirable in technologies management), and the upper level is equal to 0.8 , which will be responsible for good LRS in technologies management (2).

Since " $x$ " corresponding to the desirability level of 0.2 takes a negative value, that causes inconvenience in calculations, then formula (3) will be represented as follows:

$$
d(x)=e^{-e^{-(x-2)}} .
$$

One or another desired optimization level of the parameter is taken as "desirability" d. Taking into account the accepted assumptions, the value of $\mathrm{d}$ is in the range from 0.2 to 0.8 , and for the risk indicators for ( 1$)$ there is a range: $1<\mathrm{Ii}<4$. Taking this into account, $\mathrm{d}$ will reflect the degradation degree of the LRS of agrolandscapes in Table 3. An optimized risk safety scale (HSSR) is obtained using the Harrington method.

Table 3. HSSR Security risk scale.

\begin{tabular}{|c|c|c|c|}
\hline Risk indicator & $\begin{array}{c}\text { Reclamation status of the } \\
\text { agrolandscape }\end{array}$ & $\begin{array}{c}\text { Dgradation } \\
\text { according to d }\end{array}$ & $\begin{array}{c}\text { Risk assessment of the } \\
\text { agrolandscape }\end{array}$ \\
\hline $\mathrm{I}_{\mathrm{i}}=1$ & no risks & $>0,8$ & "perfect" \\
\hline $1<\mathrm{I}_{\mathrm{i}} \leq 2$ & not exposed to risks & $0,6-0,8$ & "good" \\
\hline $2<\mathrm{I}_{\mathrm{i}} \leq 3$ & in an unstable state & $0,4-0,6$ & "satisfactory " \\
\hline $3<\mathrm{I}_{\mathrm{i}} \leq 4$ & in a critical state & $0,2-0,4$ & "unsatisfactory" \\
\hline $\mathrm{I}_{\mathrm{i}}>4$ & is degrading & $<0,2$ & degradation \\
\hline
\end{tabular}

The data in Table 3 of the HSSR shows that the indicators change in the new optimized d risk range, which varies from 0 to 1 according to the logarithmic law. Thus, the obtained upgraded risk scale of the desirability function HSSR allows to increase the accuracy of determining the LRS by the integrated risk indicator (1).

According to function (3) and Table 1, the dependence of $\mathrm{d}$ on Ii is found, which has limitations on desirability of $0.2<\mathrm{d}<0.8$ and resources of $1<\mathrm{Ii}<4$ (Figure 1 ). 


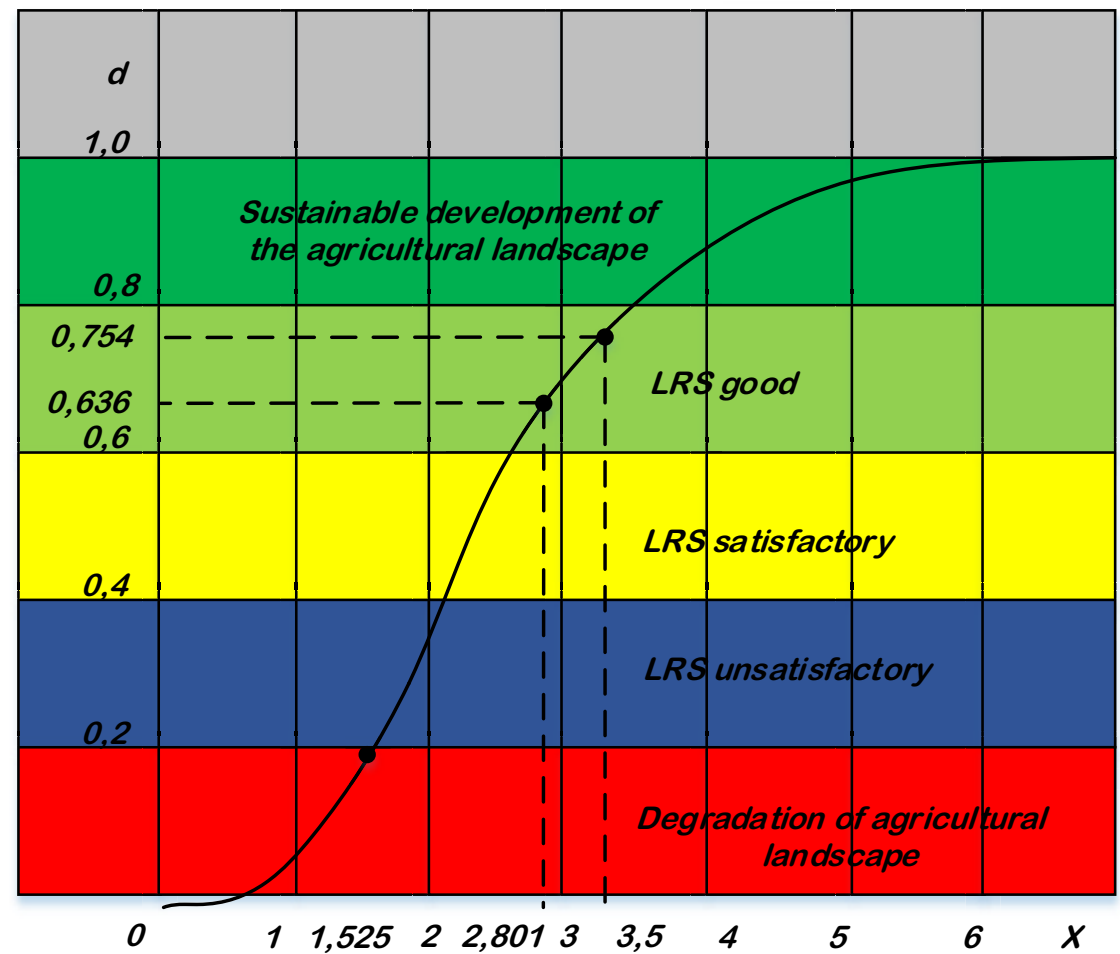

Fig. 1. Graphical solution for optimizing risk indicators according to the Harrington desirability function.

The graph shows the risks according to the state of the land resources LRS (the colored zones). Figure 1 shows not only the quantitative state of the LRS in terms of desirability risks d, but also defines the qualitative change of the resource over time, depending on the technology application. So, as illustrated by two indicators (Figure 1) with different physical entity I1 (the content of soil aggregate fraction, \%) and I7 (salt content in soil, \%), by function (3) the "desirability" $d$ is found. This means that the land resources are in a good state according to the LRS. For the indicator I1, d1 $=0.638$ and-I7, d7 $=0.754$ at $0.6<\mathrm{d}(\mathrm{x})<0.8$.

The desirability function (3) and the HSSR risk safety scale (Table 3) correspond to the properties of the resource model, integrate risks using dimensionless desirability $\mathrm{d}$ indicators of different kinds, and monitor changes in resources when technologies are applied. The complex assessment of the reclamation state of the landscape LRS is determined by the generalized indicator of the desirability function $\mathrm{D}$ :

$$
D=\sqrt[n]{\sum_{1}^{n} d_{i}^{K i}}
$$

where $\mathrm{D}$ is the generalized indicator of the HSSR desirability risk scale; $\mathrm{n}$ is the number of specific assessment i-risks; $\mathrm{Ki}$ is the weight coefficient of each i-risk; di is the desirability of the i-risk in fractions of 1 .

The authors developed the assessment methodology for LRS based on the generalized indicator D. The methodology determines the qualitative state and dynamics of resource 
changes over time, depending on the application of technologies, and allows you to manage ARPL components.

\section{Conclusions}

Methods of LRS management that allow to ensure the choice of a set of measures for the cultivation of agricultural crops by limiting the integrated risk indicator have been developed. The risk management method is based on the critical LRS of the agrolandscape taxon, which is determined by a dimensionless integral risk indicator. The value of the parameter IIRk, at which the agricultural landscape goes into a state of degradation, has been established.

The SSR risk safety scale was optimized using the Harrington method. The desirability function is used to optimize indicators and also shows that the integrated risk indicators, that can be numerous I1, I $2 \ldots$ I $n, I n+1$... adequately correspond to the desirability of $\mathrm{d} 1$, $\mathrm{d} 2 \ldots \mathrm{dn} \mathrm{dn}+1 \ldots$ The upgraded risk scale of the HSSR desirability function has been obtained. It allows to increase the accuracy of LRS determination by the integrated risk indicator (1).

The complex ARPL management is performed according to a generalized desirability indicator that determines the qualitative state and dynamics of resource changes over time. It also allows to manage ARPL components depending on the applied technologies.

\section{References}

1. S.T. Larned, T. Datry, D.B. Arscott, K. Tockner, Freshwater Biology, 55, 717-738 (2015)

2. E.V. Kuznetsov, A.E. Khadzhidi, K.I. Kilidi, A.N. Kurtnezirov, Plant Archives, 18 (2), 2151-2158 (2018)

3. L. Novickytè, Agric. Econ. Czech, 65, 435-444 (2019)

4. V. Njegomir, J.D. Rihter, Ekonomika Poljoprivrede (Economics of Agriculture), 65, 995-1014 (2018) https://doi.org/10.5937/ekoPolj1803995N.

5. E.V. Kuznetsov, T.I. Safronova, I.V. Sokolova, A.E. Khadzhidi, A.D. Gumbarov, Journal of Environmental Management and Tourism Biannually, VIII (17), 78-83 (2017) Journal DOI http://dx.doi.org/10.14505/jemt.

6. B. Yang, F. Meng, X. Ke, C. Ma, Hindawi Publishing Corporation Advances in Meteorology, 2015, Article ID 416728, 7 pages

http://dx.doi.org/10.1155/2015/416728

7. M.A. Bandurin, I.F. Yurchenko, I.P. Bandurina, International Multi-Conference on Industrial Engineering and Modern Technologies, FarEastCon, 8933970 (2019)

8. W. Dong, X. Zhang, H. Wang, X. Dai, X. Sun, W. Qiu, et al., PLoS ONE, 7 (9), e44504 (2012) https://doi.org/10.1371/journal.pone.0044504

9. G. Gram, D. Roobroeck, P. Pypers, J. Six, R. Merckx, B. Vanlauwe, PLoS ONE, 15(9), e0239552 (2020) https://doi.org/10.1371/journal.pone.0239552

10. A. Alam, International Journal of Scientific Research in Agricultural Sciences, Available online at http://www.ijsrpub.com/ijsras ISSN: 2345-6795, IJSRPUB, 1(4), 50-55 (2014) http://dx.doi.org/10.12983/ijsras-2014-p0050-0055 
11. D.Pimentel, M. Burgess, Agriculture, 3, 443-463 (2013) doi:10.3390/agriculture3030443

12. S.B.R. Reartes, V. Estrada, R. Bazan, N. Larossa, A. Cossavella, A. Lopez, F. Busso, M.S. Diaz, Influence of Extreme Strength in Water Quality of the Jucazinho Reservoir, Northeastern Brazil, PE, 320, 393-406 (2016) Avialable from: https://www.researchgate.net/publication/321658767_Influence_of_Extreme_Strength in_Water_Quality_of_the_Jucazinho_Reservoir_Northeastern_Brazil_PE [accessed Feb 16 2021]

13. A.E. Khadzhidi, Scientific journal: Works of KubSAU, 5(38), 169-173 (2012)

14. R. R. Camara de Melo and J. R. Gonçalves de Azevedo. Revista Brasileira de Recursos Hídricos Brazilian Journal of Water Resources, Porto Alegre, 21 (4), 871881 (2016)

15. J. Przybyłek, K. Dragon, P. Michał, J. Kaczmarek, Geologos 23(3), 201-214 (2017) doi: 10.1515/logos-2017-0021 